\title{
A Simple Method for Iodination of Benzo- and Dibenzocrown Ethers
}

\author{
Sergei M. Pluzhnik-Gladyr, Ildar M. Rakipov, and Sergei A. Kotlyar ${ }^{@}$ \\ A. V. Bogatsky Physico-Chemical Institute of National Academy of Sciences of Ukraine, Odessa, 65080, Ukraine \\ @Corresponding author_E-mail: kotlyar_sk@mail.ru
}

\begin{abstract}
Iodination of benzo-12-crown-4, benzo-15-crown-5 and benzo-18-crown-6 by equimolar amounts of $N$-iodosuccinimide in ethanol in the presence of sulfuric acid additions proceeds quickly and selectively and results in corresponding $4^{I}$-iododerivatives with 78-86\% yields. Reactivity of [3.3] dibenzo-18-crown-6 slightly differs from that of benzocrown ethers and diiodide (mixture of cis- and trans-isomers) is obtained with $76 \%$ yield.
\end{abstract}

Keywords: Benzo- and dibenzocrown ethers, N-iodosuccinimide, selective iodination.

\section{Простой способ иодирования бензо- и Аибензокраун-эфиров}

\author{
С.М. Плужник-Гладырь, И.М. Ракипов, С.А. Котляр ${ }^{@}$ \\ Физико-химический институт им. А. В. Богатского Национальной академии наук Украины, г. Одесса, 65080, Украина \\ @E-mail: kotlyar_sk@mail.ru
}

\begin{abstract}
Иодирование бензо-12-краун-4, бензо-15-краун-5 и бензо-18-краун-6 эквимолярными количествами $N$-иодсукцинимида протекает быстро и селективно в среде этанола в присутствии небольших количеств серной кислоты и приводит к соответствующим 4'-иодпроизводным с выходами 78-86\%. Реакциионная способность [3.3]дибензо-18-краун-6 мало отличается от таковой у бензокраун-эфиров, а дииодид (смесь цис- и транс-изомеров) образуется с выходом 76\%.
\end{abstract}

Ключевые слова: Бензо- и дибензокраун-эфиры, N-иодсукцинимид, селективное иодирование.

\section{Введение}

Иодзамещенные бензо- (БКЭ) и дибензокраунэфиры (ДБКЭ) легко трансформируются в труднодоступные ацетиленовые,$^{[1-3]}$ винильные ${ }^{[4,5]} H$-алкильные, $H$-гидроксиалкильные, ${ }^{[6]}$ биологически активные аммониевые и фосфониевые ${ }^{[7]}$ производные, а также краун-гетероциклы, ${ }^{[8]}$ бис-бензокраун-эфиры ${ }^{[3,6]}$ и др.

В то же время, методы введения иода в ароматические фрагменты краун-соединений изучены явно недостаточно. Иодирование последних проводят в системах, содержащих сильные окислители, а именно, $\mathrm{I}_{2}-\mathrm{HIO}_{3}-\mathrm{H}_{2} \mathrm{SO}_{4}{ }^{[9,10]} \mathrm{I}_{2}-\mathrm{CF}_{3} \mathrm{COOAg}^{[5]}$ и $\mathrm{HI}-\mathrm{H}_{2} \mathrm{O}_{2}{ }^{[11]}$ либо иоддихлоридом триметилбензиламмония в среде $\mathrm{CH}_{3} \mathrm{COOH}$ в присутствии безводного $\mathrm{ZnCl}_{2} \cdot{ }^{[12]}$ Однако, по различным причинам обсуждаемые методики не масштабируются.

Перспективными источниками электрофильного иода, обладающего суперактивными свойствами либо повышенной реакционной способностью при иодировании ароматических соединений, ${ }^{[13-18]}$ являются хлористый иод, тетраиодгликурил и $\mathrm{N}$-иодсукцинимид, а соответствующие процессы протекают в среде $\mathrm{H}_{2} \mathrm{SO}_{4}$ высокой концентрации (90-95\%). В этих условиях ио- дирование таких субстратов, как БКЭ и ДБКЭ, в значительной степени осложнено побочными процессами протонирования, осмоления, сульфирования и др.

В отдельных случаях алкилбензолы, ароматические амины, фенолы и некоторые другие субстраты, ${ }^{[19]}$ реагируют с N-иодсукцинимидом в органических растворителях в присутствии небольших количеств $\mathrm{H}_{2} \mathrm{SO}_{4}$.

Недавно ${ }^{[20]}$ нами обнаружено, что при «нейтральном» иодировании БКЭ и ДБКЭ в среде кипящего $\mathrm{CHCl}_{3}$ реакционная способность $\mathrm{N}$-иодсукцинимида заметно ниже сравнительно с его хлор- и броманалогами. Если для последних, указанные макроциклы, в зависимости от стехиометрии реакции, с хорошими либо высокими выходами селективно трансформируются в соответствующие моно- или дигалогенпроизводные, только БКЭ под действием N-иодсукцинимида претерпевают моноиодирование (выходы продуктов лишь 20-30\%).

Продолжая исследования в области синтеза, изучения строения и свойств галогенпроизводных БКЭ и ДБКЭ, ${ }^{[11,20-26]}$ мы предприняли попытку разработать простой и селективный способ иодирования, общий для этих ароматических макрогетероциклов. 


\section{Экспериментальная часть}

Температуры плавления определяли на приборе ПТП1 в запаянных и открытых капиллярах, скорость нагревания $4^{\circ} \mathrm{C} /$ мин. Краун-соединения 1-4 содержали не менее 98\% основного вещества (ГЖХ), соединения-свидетели 5-8 получены по известным методикам. ${ }^{[9-11]} \mathrm{N}$-иодсукцинимид (т.пл. 200-201 ${ }^{\circ} \mathrm{C}$ ) получали двумя различными способами, аналогично описанным в работах ${ }^{[18,27]}$ и тщательно очищали до содержания основного вещества (титриметрия) не менее 98-99\%. Использовали $\mathrm{H}_{2} \mathrm{SO}_{4}$ квалификации «х.ч.».

Спектры ${ }^{1} \mathrm{H}$ ЯМР записывали на спектрометре Varian WXR-300, с рабочей частотой $300 \mathrm{MГц,} \mathrm{в} \mathrm{растворах} \mathrm{CDCl}_{3}$, внутренний стандарт $\mathrm{Me}_{4} \mathrm{Si}$. Масс спектры получали на массспектрометре MX 1321 с использованием системы прямого ввода ESI (ионизирующее напряжение 70 эВ, температура камеры ионизации $220^{\circ} \mathrm{C}$ ). ТСХ проводили на пластинах Silufol UV254 (Kavalier) в следующих системах растворителей: $\mu$-гексан:этилацетат $=7: 3, \mu$-гексан:ацетон $=3: 1$, этилацетат, $\mu$-гексан:хлороформ $=7: 3,5: 2$ либо 2:1 (проявление в УФ свете и парах иода).

\section{Иодирование краун-эфиров 1-3}

К раствору 7,5 ммоль КЭ 1-3 в 15 мл этанола, при перемешивании и охлаждении $\left(10-15^{\circ} \mathrm{C}\right)$ прибавляли 1,5 мл концентрированной $\mathrm{H}_{2} \mathrm{SO}_{4}$. В течение 5 мин (не выше $20^{\circ} \mathrm{C}$ ), при интенсивном перемешивании прибавляли небольшими порциями хорошо измельченный свежеочищенный $\mathrm{N}$-иодсукцинимид (1,69 г, 7,5 ммоль) и перемешивали 30 мин. Реакционную смесь разбавляли 50-70 мл 3\%-ного раствора $\mathrm{Na}_{2} \mathrm{SO}_{3}$, перемешивали до обесцвечивания, доводили до $\mathrm{pH} 7$ раствором $\mathrm{Na}_{2} \mathrm{CO}_{3}$, фильтровали, твердый продукт промывали водой (5-10 мл). Сушили до постоянной массы, при необходимости, кристаллизовали из $H$-гептана.

4'-Иодбензо-12-краун-4, 5: Выход 2,26 г (86\%), т. пл. $72-$ $73{ }^{\circ} \mathrm{C}$. Найдено, \%: С 41,10, Н 4,21, I 36, 12. $\mathrm{C}_{12} \mathrm{H}_{15} \mathrm{IO}_{4}$. Вычислено,

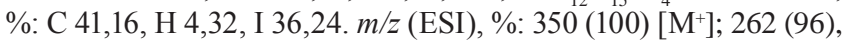
263 (11) $\left[\left(\mathrm{M}-\left(\mathrm{CH}_{2} \mathrm{CH}_{2} \mathrm{O}\right)_{2}\right)\right]^{+} .{ }^{1} \mathrm{H}$ ЯMP $\left(\mathrm{CDCl}_{3}, 298 \mathrm{~K}\right) \delta_{\mathrm{H}}$ м.д.: 7,27-7,23 (2H, д, $J=9,0 \mathrm{~Hz}, \mathrm{Ar}), 6,75-6,71(1 \mathrm{H}$, д, $J=9,0 \mathrm{~Hz}, \mathrm{Ar})$, 4,18-4,14 (4H, т, $\left.J=4,4 \mathrm{~Hz}, \mathrm{OCH}_{2}\right), 3,87-3,84(4 \mathrm{H}, \mathrm{T}, J=4,4 \mathrm{~Hz}$, $\left.\mathrm{CH}_{2} \mathrm{O}\right), 3,78\left(4 \mathrm{H}, \mathrm{c}, \mathrm{OCH}_{2} \mathrm{CH}_{2} \mathrm{O}\right)$.

4'-Иодбензо-15-краун-5, 6: Выход 2,31 г (78 \%), т. пл. 81$82^{\circ} \mathrm{C}$. Найдено, \%: C 42,55, Н 4,73, I 32,05. $\mathrm{C}_{14} \mathrm{H}_{19} \mathrm{IO}_{5}$. Вычислено, \%: C 42,66, H 4,86, I 32,19. m/z (ESI), \%: 394 (49) [M+]; 262 (100)
$\left[\left(\mathrm{M}-\left(\mathrm{CH}_{2} \mathrm{CH}_{2} \mathrm{O}\right)_{3}\right)\right]^{+} .{ }^{1} \mathrm{H}$ ЯМР $\left(\mathrm{CDCl}_{3}\right) \delta_{\mathrm{H}}$ м.д.: 7,21-7,18 $(1 \mathrm{H}$, дд, $J=8,4 \mathrm{~Hz}, J=1,85 \mathrm{~Hz}, \mathrm{Ar}), 7,15-7,12(1 \mathrm{H}$, д, $J=1,85 \mathrm{~Hz}, \mathrm{Ar}), 6,65-$ $6,60(1 \mathrm{H}$, д, $J=8,4 \mathrm{~Hz}, \mathrm{Ar}), 4,13-4,09\left(4 \mathrm{H}, \mathrm{T}, J=4,4 \mathrm{~Hz}, \mathrm{CH}_{2} \mathrm{CH}_{2} \mathrm{O}\right)$, 3,92-3,88 (4H, т, $\left.J=4,4 \mathrm{~Hz}, \mathrm{CH}_{2} \mathrm{CH}_{2} \mathrm{O}\right), 3,77$ (8H, с, $\left.\mathrm{CH}_{2} \mathrm{CH}_{2} \mathrm{O}\right)$.

4'-Иодбензо-18-краун-6, 7: Выход 2,73 г (83\%), т. пл. 107-109 ${ }^{\circ} \mathrm{C}$. Найдено, \%: С 43,71, Н 5,18, I 28,81. C ${ }_{16} \mathrm{H}_{23} \mathrm{IO}_{6}$. Вычислено, \%: С 43,85, Н 5,29, I 28,96. $\mathrm{m} / z$ (ESI), \%: 438 (43) $\left[\mathrm{M}^{+}\right] ; 262(100)\left[\left(\mathrm{M}-\left(\mathrm{CH}_{2} \mathrm{CH}_{2} \mathrm{O}\right)_{4}\right)\right]^{+} .{ }^{1} \mathrm{H}$ ЯMP $\left(\mathrm{CDCl}_{3}\right) \delta_{\mathrm{H}}$ м.д.: 7,24 (1H, c, Ar), 7,12-7,08 (1H, д, J=8,4 Hz, Ar), 6,82-6,78 (1H, д, $\mathrm{J}=8,4 \mathrm{~Hz}, \mathrm{Ar}), 4,15-4,12\left(4 \mathrm{H}, \mathrm{T}, \mathrm{J}=4,4 \mathrm{~Hz}, \mathrm{OCH}_{2}\right), 3,92-3,90(4 \mathrm{H}$, T, J=4,4 Hz, $\left.\mathrm{CH}_{2} \mathrm{O}\right), 3,86-3,80\left(8 \mathrm{H}, \mathrm{m}, \mathrm{OCH}_{2} \mathrm{CH}_{2} \mathrm{O}\right), 3,68(4 \mathrm{H}, \mathrm{c}$, $\mathrm{OCH}_{2} \mathrm{CH}_{2} \mathrm{O}$ ).

$4^{I}, 4^{I I},\left(5^{I I}\right)$-Дииод [3.3]дибензо-18-краун-6, смесь ичисu транс-изомеров, 8. Получали аналогично описанному выше, используя раствор макроцикла 4 (2,70 г, 7,5 ммоль) в 45 мл этанола, конц. $\mathrm{H}_{2} \mathrm{SO}_{4}$ (3 мл) и $\mathrm{N}$-иодсукцинимид (3,38 г, 15,0 ммоль), кристаллизовали последовательно из метилцеллозольва и толуола. Выход 3,49 г (76\%), т. пл. 179$184{ }^{\circ} \mathrm{C}$. Найдено, \%: С 39,19, Н 3,65, I 41,20. $\mathrm{C}_{20} \mathrm{H}_{22} \mathrm{I}_{2} \mathrm{O}_{6}$. Вычислено, \%: С 39,24, Н 3,62, I 41,46. m/z (ESI), \%: 612 (100),

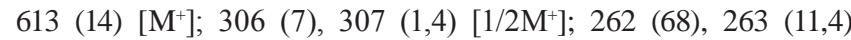
$\left[1 / 2 \mathrm{M}^{+}-\mathrm{CH}_{2} \mathrm{CH}_{2} \mathrm{O}\right] .{ }^{1} \mathrm{H}$ ЯMP $\left(\mathrm{CDCl}_{3}\right) \delta_{\mathrm{H}}$ м.д.: 3,96-4,05 (8H, м, $\left.2 \mathrm{CH}_{2} \mathrm{OCH}_{2}\right), 4,09-4,19\left(8 \mathrm{H}, \mathrm{m}, 4 \mathrm{ArOCH}_{2}\right), 6,59(2 \mathrm{H}$, д), 7,10 (2H, c), $7,18(2 \mathrm{H}$, д).

\section{Обсуждение результатов}

Обнаружено, что бензо-12-краун-4 (1), бензо15 -краун-5 (2) и бензо-18-краун-6 (3), подобно некоторым другим ароматическим соединениям, ${ }^{[19]}$ быстро и селективно иодируются эквимолярными количествами $\mathrm{N}$-иодсукцинимида в среде этанола в присутствии небольших количеств $\mathrm{H}_{2} \mathrm{SO}_{4}$, образуя соответствующие 4'-иодБКЭ 5-7 (выходы 78-86\%) (Схема 1). Аналогично, иодирование [3.3]дибензо18-краун-6 (4) при соотношении ДБКЭ:имид $=1: 2$, приводит к дииодпроизводному 8 (смесь циис- и трансизомеров) с выходом 76\%.

Процесс осуществляли перемешиванием реакционной смеси, содержащей стехиометрические количества реагентов, в течение 30 мин, при комнатной температуре. Соотношение этанол: $\mathrm{H}_{2} \mathrm{SO}_{4}$ составляло 10:1 (по объему) для соединений 1-3, и 15:1 для макроцикла 4.

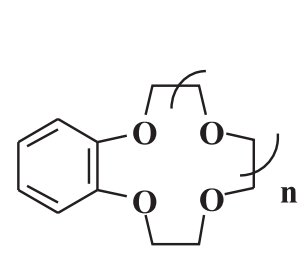

1 - 3

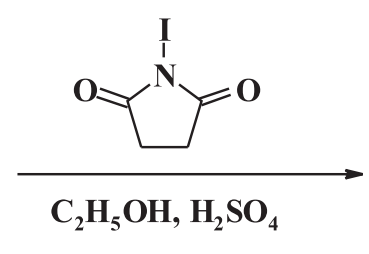

$20{ }^{\circ} \mathrm{C}$

$\mathrm{n}=1-3$<smiles>CCOCCOc1ccc(I)cc1OCCOCCO</smiles>

$5-7$<smiles></smiles>

4

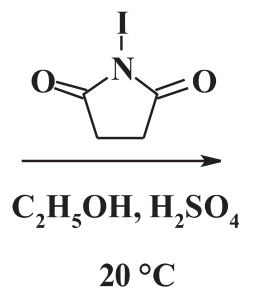

$20{ }^{\circ} \mathrm{C}$<smiles>Ic1ccc2c(c1)OCCOCCOc1ccccc1OCCOCCO2</smiles>

Схема 1. 
Отметим, что в условиях эксперимента, в противоположность исследованному ранее иодированию в среде кипящего $\mathrm{CHCl}_{3}$, ${ }^{[20]}$ реакционные способности исследованных БКЭ 1-3 и ДБКЭ 4 практически не различаются.

Предложенный способ выделения целевых продуктов 5-8 достаточно прост. При обработке не вступившие в реакцию субстраты 1-3 растворяются в объеме воды, а последующая нейтрализация раствора исключает потери продуктов 5-7 из-за возможного растворения в воде в протонированной форме.

По данным масс-спектрометрии и ТCX, при стехиометрическом соотношении реагентов краунсоединения 1-4 конвертируют полностью, а в реакционной смеси и неочищенных продуктах реакции практически отсутствуют дииодиды (для 1-3) либо моно- и трииодиды (для 4). В то же время, использование даже незначительного (5-10\%) избытка иодирующего агента, во всех случаях приводит к появлению примесей.

При увеличении соотношения N-иодсукцинимид:субстрат 1-3 в 2 раза нами получены смеси 4'-иоди $4^{\mathrm{I}}, 5^{\mathrm{I}}$-дииодБКЭ с преобладанием первых, а из макроцикла 4 с выходом 70\% образуется дииодид 8 (т. пл. $\left.180-182^{\circ} \mathrm{C}\right)$, содержащий незначительные примеси субстрата, моно- и трииодида.

Синтезированные соединения 5-8 идентифицированы с помощью ${ }^{1} \mathrm{H}$ ЯМР спектроскопии, массспектрометрии, элементного анализа, путем сопоставления их физико-химических характеристик с таковыми для соединений-свидетелей, синтезированных по известным методикам, а чистота установлена ТСХ.

\section{Выводы}

Создание систем с регулируемой активностью электрофильного иода, «настроенных» на определенные группы субстратов, является актуальной задачей. Иодирующая система, в состав которой входят N-иодсукцинимид, этанол и $\mathrm{H}_{2} \mathrm{SO}_{4}$, показала высокую эффективность и селективность при иодировании как БКЭ, так и ДБКЭ за короткий промежуток времени при комнатной температуре.

На наш взгляд, предложенный простой способ иодирования ароматических краун-соединений обладает рядом несомненных преимуществ, сравнительно с описанными ранее. ${ }^{[5,9-12,20]}$ Доказательство предполагаемого механизма реакции и выявление возможного влияния краун-соединения на реакционную способность N-иодсукцинимида, является целью наших дальнейших исследований.

\section{Список литературы}

\section{References}

1. Klyatskaya S.V., Tretyakov Y.V., Vasilevskiy S.F. Izv. Ross. Akad. Nauk, Ser. Khim. 2002, 9, 1579-1581. (in Russ.).

2. Klyatskaya S.V., Tretyakov E.V., Vasilevskiy S.F. Mendeleev Commun. 1998, 5, 201-203.
3. Koenig B., Schofield E., Jones P.G., Bubenitschek P. J. Org. Chem. 1994, 59, 7142-7143.

4. Liao Yi, Zhang Zhuangyu, Hu Hongwen. Synth. Commun. 1995, 25, 595-601.

5. Kikukawa K., Takamura S., Hirayama H., Namiki H., Wada F., Matsuda T. Chem. Lett. 1980, 5, 511-514.

6. Kikukawa K., Abe A., Wada F., Matsuda T. Bull Chem. Soc. Jap. 1983, 56, 961-962.

7. Lukoyanov N.V., Vankin G.I., Malygin V.V., Kalchenko V.I., Parkhomenko N.A., Atamas L.I., Pacheva L.M., Galenko T.G., Ivanova T.A., Panarin V.A., Raevskii O.A., Markovskii L.N. Khim. Farm. Zh. 1991, 25, 36-38. (in Russ.).

8. Takeshlta M., Irie M. J. Org. Chem. 1998, 63, 6643-6649.

9. Klyatskaya S.V., Tretyakov E.V., Vasilevskiy S.F. Arkivoc. 2003, 13, 21-34.

10. Hyde E.M., Shaw, B.L., Shepherd I. J. Chem. Soc. Dalton Trans. 1978, 1696-1705.

11. Kotlyar S.A., Pluzhnik-Gladyr S.M. In Monomery dlya termoustoichivych polimerov [Monomers for Thermal Resistant Polymers]. Moskva, NIITEKHIM, 1990, 74-80. (in Russ.).

12. Takeshita M., Masahiro I. Tetrahedron Lett. 1998, 39, 613616.

13. Tchaikovskiy V.K., Kharlova T.S., Filimonov V. D. Izv. Ross. Akad. Nauk, Ser. Khim. 1999, 7, 1303-1306. (in Russ.).

14. Tchaikovskiy V.K., Kharlova T.S., Filimonov V.D., Saryucheva T.A. Synthesis 1999, 5, 748-750.

15. Tchaikovskiy V.K., Filimonov V.D., Kharlova T.S., Chernova T.N., Sharapova E. S. Zh. Org. Khim. 2000, 36, 693-697. (in Russ.).

16. Tchaikovskiy V.K., Kharlova T.S., Tretyakov Y.V., Vasilevskiy S.F., Filimonov V.D. Izv. Ross. Akad. Nauk, Ser. Khim. 2000, 8, 1482-1484. (in Russ.).

17. Tchaikovskiy V.K., Filimonov V.D., Yagovkin A.Yu., Kharlova T.S. Tetrahedron Lett. 2000, 41, 9101-9104.

18. Tchaikovskiy V.K., Skorokhodov V.I., Filimonov V.D. Zh. Org. Khim. 2001, 37, 1572-1573. (in Russ.).

19. Tchaikovskiy V.K., Filimonov V.D. Izv. Vyssh. Uchebn. Zaved., Ser. Khim. i Khim. Tekhn. 2002, 45, 48-51. (in Russ.).

20. Kotlyar S.A., Pluzhnik-Gladyr S.M. Macroheterocycles 2008, 1, 85-89.

21. Kamalov G.L., Kotlyar S.A., Grygorash R.Ya., Tkachuk V.V., Chuprin G.N., Shishkin O.V., Konup I.P., Konup L.A. In Oxygen and Sulfur Containing Heterocycles. (Kartsev V.G., Ed.). Moscow: IBS PRESS, 2003, 238-244.

22. Kotlyar S.A., Shishkina S.V., Shishkin O.V., PluzhnikGladyr S.M., Kiriyak A.V., Chuprin G.N., Kamalov G.L. Acta Crystallogr. 2006, E62, m120-m122.

23. Kotlyar S.A., Shishkina S.V., Shishkin O.V., Grygorash R. Ya., Pluzhnik-Gladyr S. M., Kamalov G. L. Acta Crystallogr. 2007, E63, o2904.

24. Atamas L.I., Kotlyar S.A., Grygorash R.Ya., PluzhnikGladyr S.M., Shishkin O.V., Shishkina S.V., Zubatyuk R.I., Kalchenko V.I., Kamalov G.L. J. Struct. Chem. 2005, 46, S9-S15.

25. Konup L.O., Konup I.P., Pluzhnik-Gladyr S.M., Kotlyar S.A. Odesskiy Med. Zh. 2006, 4, 14-17.

26. Fonari M.S., Simonov Yu.A., Bocelli G., Ganin E.V., Wang Wen-Jwu, Plyzhnik-Gladyr S.M., Tkachuk V.V., Kotlyar S.A., Kamalov G.L. J. Incl. Phen. and Macrocycl. Chem. 2008, 61, 367-375.

27. Benson W.R., McBee E.T., Rand L. Organic Syntheses Coll. 1973, 5, 663-664. 